\title{
Efeito da adição de Lactobacillus sp. na ensilagem de cana-de-açúcar ${ }^{1}$
}

\section{Alexandre Rocha Valeriano ${ }^{2}$, José Cardoso Pinto ${ }^{3}$, Carla Luiza da Silva Ávila ${ }^{4}$, Antônio Ricardo Evangelista ${ }^{3}$, Valdir Botega Tavares ${ }^{2}$, Rosane Freitas Schwan $^{5}$}

\author{
1 Projeto financiado pelo CNPq. \\ 2 Programa de Pós-graduação em Zootecnia - UFLA. \\ 3 Departamento de Zootecnia - UFLA. \\ 4 Pós-Doutorado em Zootecnia - UFLA \\ ${ }^{5}$ Departamento de Biologia - UFLA.
}

RESUMO - Objetivou-se avaliar o efeito de aditivos microbianos com bactérias heterofermentativas ou homofermentativas sobre as características de silagens de cana-de-açúcar (Saccharum spp.). A cana-de-açúcar foi inoculada com as bactérias Lactobacillus plantarum (LP), L. paracasei (LPARA), L. brevis (LBREVIS), L.buchneri (LB), isoladas da silagem de canade-açúcar, e três inoculantes comerciais, dois contendo L. buchneri (Pioneer 11A44TM-LBP e Lalsil Cana-LBLC) e um, L. plantarum (Biomax ${ }^{\circledR}$-LPB), e avaliada em comparação a uma silagem controle (sem inoculante). Todos os inoculantes foram aplicados com população de $10^{5}$ ufc da bactéria por g de forragem. O delineamento utilizado foi o inteiramente casualizado com oito tratamentos e três repetições. O efeito da inoculação sobre as características bromatológicas foi variável. A silagem contendo a bactéria L. plantarum apresentou maior teor de MS (32,6\%), enquanto, para os outros inoculantes, não houve diferença, com média de 28,4\%. Os teores de proteína bruta variaram de 3,6 a 4,9\% e os de FDN, de 60,0 a $66,7 \%$. As porcentagens de FDA, hemicelulose e cinzas foram semelhantes em todas as silagens. O consumo de carboidratos solúveis foi superior a $85 \%$ durante a fermentação, para todas as silagens, o que resultou em pH em torno de 3,5. Os valores de $\mathrm{pH}$ e nitrogênio amoniacal para todas as silagens estiveram no padrão aceitável para silagens de boa qualidade. Os inoculantes retardaram o aumento da temperatura, em aerobiose, conferindo maior estabilidade aeróbia. Os melhores resultados foram obtidos com os inoculantes LBLC, LB e LPB.

Palavras-chave: estabilidade aeróbia, fermentação, microbiologia, temperatura

\section{Effect of the addition of Lactobacillus sp. in sugarcane silages}

\begin{abstract}
This study was aimed to evaluate the effect of microbial additives containing hetero fermentative or homo fermentative bacteria on the characteristics of sugarcane silages. Sugarcane was inoculated with the following bacteria: Lactobacillus plantarum (LP), L. paracasei (LPARA), L. brevis (LBREVIS), L.buchneri (LB), isolated from sugarcane silage, and three commercial inoculants, two of them containing L. buchneri (Pioneer 11A44TM-LBP and Lalsil Cana-LBLC) and one L. plantarum (Biomax ${ }^{\circledR}$-LPB) and control (without inoculation). All the inoculants were applied in population of $10^{5} \mathrm{log} \mathrm{cfu}^{-1}$ of fresh forage. A completely randomized design was used with eight treatments and three replicates. The effect of inoculation on the bromatological characteristics was variable. The silage containing L. plantarum (LPB) showed significantly higher dry matter content (32.6\%), while all the others strains studied showed similar effect, with average of $28.4 \%$. The crude protein content ranged from $3.6-4.9 \%$ and NDF content ranged from 60-66.7\% DM. The ADF, hemicellulose and ash contents were similar for all silages. All treatments used more than $85 \%$ of the soluble carbohydrate, which resulted in $\mathrm{pH}$ around 3.5. The $\mathrm{pH}$ and ammoniacal nitrogen values were acceptable. The inoculants were more effective for the aerobic evaluation of silages, because they slow down temperature and improve the aerobic stability with best results observed in treatments LBLC, LB and LPB.
\end{abstract}

Key Words: aerobic stability, fermentation, microbiology, temperature

\section{Introdução}

A cana-de-açúcar é uma forrageira de grande importância na alimentação animal. Tradicionalmente, é colhida diariamente, picada e fornecida aos animais, entretanto, o corte diário tem algumas desvantagens, como a demanda de mão-de-obra diária para cortes, despalhamento e picagem (Nussio et al., 2003).

A possibilidade do uso da cana-de-açúcar na forma de silagem pode ser uma alternativa para resolver os problemas 
do corte diário, todavia, essa silagem apresenta intensa fermentação alcoólica por leveduras (Kung Jr. \& Stanley, 1982). Em condições anaeróbias, as leveduras fermentam açúcares a etanol e $\mathrm{CO}_{2}$. Esse etanol produzido não somente diminui a quantidade de açúcar disponível para as bactérias do ácido lático, mas também tem efeito negativo sobre o sabor do leite. Em condições aeróbias, muitas espécies de levedura degradam o ácido lático, causando aumento do pH da silagem (McDonald et al., 1991).

A ensilagem de cana-de-açúcar sem aditivos tem resultado em perdas de até 30\% da MS, o que ocasiona acúmulo de componentes da parede celular e redução da digestibilidade in vitro da matéria seca (Ferreira et al., 2007). Além disso, as silagens apresentam alto teor de carboidrato residual e ácido lático, substratos potencialmente utilizáveis pelos microrganismos deterioradores da silagem após a abertura dos silos (McDonald et al., 1991). Com isso, nos últimos anos, tem crescido o interesse, principalmente de pesquisadores brasileiros, por aditivos para ensilagem de cana-deaçúcar capazes de inibir o crescimento de leveduras.

Bactérias produtoras de ácido lático têm sido estudadas como inoculantes em silagens e atualmente tem sido maior a atenção à adição de bactérias heteroláticas, principalmente da espécie Lactobacillus buchneri, a qual tem apresentado resultados promissores principalmente na inibição do crescimento de fungos e no aumento da estabilidade aeróbia (Filya et al., 2003). Ávila (2007) observou que cepas homofermentativas da espécie Lactobacillus plantarum e Lactobacillus paracasei e heterofermentativas da espécie Lactobacillus brevis cresciam com maior frequência durante todo o processo de fermentação da cana-de-açúcar. Com base nestes dados, objetivou-se com este trabalho avaliar o efeito de aditivos microbianos com bactérias heterofermentativas ou homofermentativas, isolados em silagens de cana-de-açúcar e de inoculantes comerciais, sobre as características bromatológicas e a estabilidade aeróbia de silagens de cana-de-açúcar (Saccharum spp.).

\section{Material e Métodos}

O experimento foi conduzido nos Departamentos de Zootecnia e Biologia da Universidade Federal de Lavras, Minas Gerais. A cana-de-açúcar utilizada no experimento foi colhida de um canavial estabelecido em área pertencente àUFLA, variedade RB72454, com idade de rebrota de 12 meses, na estação seca (mês de junho), quando apresentou $18^{\circ}$ Brix. A colheita foi manual e, em seguida, a cana foi picada em picadeira estacionária sem sofrer despalhamento, proporcionando partículas em torno de 20 mm para produção da silagem.
Os inoculantes foram previamente preparados no Laboratório de Microbiologia do Departamento de Biologia da UFLA a partir de cepas isoladas da silagem de cana-deaçúcar por Ávila (2007). Para tanto, foram retiradas amostras da silagem da cana-de-açúcar e preparados extratos com água peptonada estéril. A partir do extrato obtido, foram preparadas diluições decimais em série para posterior espalhamento em meio MRS (De Man Rogosa Sharpe, Difco). Após o espalhamento, as placas foram incubadas a $30^{\circ} \mathrm{C}$ por 48 horas. Das placas contendo 30 a 300 colônias, foram isolados os microrganismos para posterior identificação (Holt et al., 1994). Foram realizados os testes de coloração de Gram, catalase, motilidade e da produção de gás para todos os isolados. Com base nos testes bioquímicos, os isolados foram classificados como pertencentes ao gênero Lactobacillus, conforme recomendado no Bergey's Manual of Determinative Bacteriology (Holt et al., 1994) e The Prokaryotes (Hammes \& Hertel, 2003), e as espécies identificadas utilizando-se o kit API 50 CHL (BioMerieux, Marcy I'Toile, France).

As bactérias isoladas da própria silagem foram: Lactobacillus plantarum, Lactobacillus paracasei, Lactobacillus brevis e Lactobacillus buchneri. As bactérias utilizadas dos produtos comerciais foram: L. buchneri, encontrada no produto Pioneer 11A44TM (LBP); L. buchneri, encontrada no produto Lalsil Cana (LBLC); e a espécie $L$. plantarum, encontrada no produto Biomax $^{\circledR}$ (LPB) (Tabela 1). Apesar de os inoculantes apresentarem em sua composição populações diferentes de bactéria ativa por grama do produto, todos foram pesados e adicionados em quantidades que resultassem em uma população de $10^{5}$ ufc de bactéria/grama de forragem no momento da ensilagem.

No caso dos tratamentos contendo as bactérias isoladas da própria silagem de cana-de-açúcar, também se teve o cuidado de adicionar a mesma concentração de células viáveis que foi adicionada com os inoculantes comerciais. Assim, as cepas bacterianas congeladas em criotubos contendo glicerol a $-80^{\circ} \mathrm{C}$ foram reativadas em meio de cultura MRS (De Mann Rogosa Sharpe, Dfico). Posteriormente, o microrganismo foi cultivado em tubos contendo $2 \mathrm{~mL}$ de meio MRS por 24 horas e, em seguida, foi transferido para tubos contendo $10 \mathrm{~mL}$ de caldo MRS por mais 24 horas. Finalmente, foi transferido para erlenmeyer com $250 \mathrm{~mL}$ de caldo MRS e cultivado por 24 horas. Após esse período, foi feita a contagem do número de células viáveis, pelo plaqueamento em superfície em meio MRS, obtendo-se um resultado aproximado de $9 \log \mathrm{ufc} / \mathrm{mL}$ do caldo. Para cada tratamento, foi retirado $0,3 \mathrm{~mL}$ do caldo presente no erlenmeyer, o qual foi, posteriormente, misturado com 


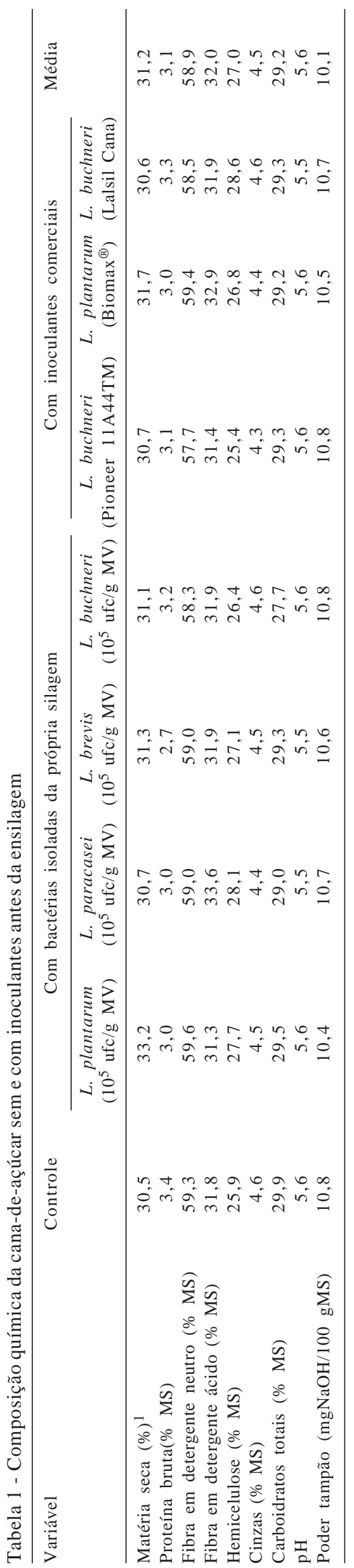

$80 \mathrm{~mL}$ de água destilada estéril e borrifado sobre $3 \mathrm{~kg}$ de forragem no momento da ensilagem. Ao final, os inoculantes foram aplicados na concentração de $10^{5} \mathrm{ufc} / \mathrm{g}$ de forragem.

A forragem picada foi compactada manualmente nos silos, com o auxílio de uma barra de ferro, em temperatura ambiente e sob a proteção da luz solar e de chuvas. Foram utilizados silos de PVC com diâmetro de $10 \mathrm{~cm}$ e altura de $60 \mathrm{~cm}$, adaptados com válvula tipo Bunsen, com capacidade para 2,5 a 3,0 kg de forragem, utilizando-se densidade de aproximadamente $600 \mathrm{~kg} / \mathrm{m}^{3}$. As soluções foram misturadas à forragem, no momento da ensilagem, com auxílio de borrifador (um para cada tratamento). Houve o cuidado de adicionar à silagem controle somente água destilada estéril, na mesma quantidade de água adicionada junto aos inoculantes $(80 \mathrm{~mL})$.

Os silos foram mantidos fechados por 90 dias. Após esse período, a silagem foi retirada para análises, tomando-se o cuidado de desprezar as extremidades da silagem no silo (aproximadamente $10 \mathrm{~cm}$ ). Antes da ensilagem e após abertura dos silos, foram retiradas três amostras; uma foi pesada e seca em estufa de ventilação forçada a $65^{\circ} \mathrm{C}$, outra foi colocada em sacos plásticos devidamente identificados e congelados e outra de $10 \mathrm{~g}$ foi retirada para determinação do $\mathrm{pH}$ usando potenciômetro Beckman Expandomatic SS-2.

As análises bromatológicas da forragem fresca e das silagens foram realizadas no Laboratório de Pesquisa Animal do Departamento de Zootecnia, da Universidade Federal de Lavras. As amostras secas foram trituradas em moinho do tipo Willey, com peneira de 30 mesh, e armazenadas em potes plásticos devidamente identificados, para avaliação dos teores de matéria seca (MS) e proteína bruta (PB), conforme métodos recomendados pela AOAC (1990); e fibra em detergente neutro (FDN) e fibra em detergente ácido (FDA), segundo técnicas descritas por Silva (1990). Os teores de hemicelulose foram obtidos pela diferença entre FDN e FDA e a matéria mineral (cinzas) foi obtida após incineração de amostras em mufla a $550^{\circ} \mathrm{C}$ durante 3 horas (Harris, 1970).

Os teores de carboidratos solúveis também foram determinados em amostras secas, conforme técnica de Bailey (1977), modificada por Valadares Filho (1981). As amostras congeladas foram descongeladas para extração do suco, com prensa hidráulica, para determinação dos teores de nitrogênio amoniacal em porcentagem do nitrogênio total [N-NH $\mathrm{NH}_{3}(\% \mathrm{~N}$ total)] (AOAC, 1980). O poder tampão no momento da ensilagem foi determinado utilizando-se amostras congeladas de acordo com técnica descrita por Playne \& McDonald (1966). 
Todo o conteúdo da silagem restante (2,0 a 2,5 kg) foi acondicionado em baldes plásticos de $8 \mathrm{~L}$, onde permaneceu por cinco dias para avaliação da temperatura das silagens em aerobiose. Essas amostras foram mantidas em sala fechada onde foi monitorada a temperatura de cada amostra diariamente. Para isso, um termômetro de mercúrio foi inserido na massa ensilada, na profundidade $10 \mathrm{~cm}$, durante cinco dias, permitindo a tomada de temperatura duas vezes ao dia (às $8 \mathrm{~h}$ e às $17 \mathrm{~h}$ ). A temperatura ambiente foi medida com auxílio de um termômetro localizado próximo aos baldes e apresentou média de $23,9^{\circ} \mathrm{C}$ e variação entre 22,5 e $25^{\circ} \mathrm{C}$. A dinâmica da temperatura da silagem ao longo do tempo foi avaliada com base na temperatura ambiental.

Utilizou-se delineamento experimental inteiramente casualizado, com oito tratamentos e três repetições. Os dados foram analisados estatisticamente pelos procedimentos de análise de variância, de acordo com o software SISVAR (Ferreira, 2000). Na comparação de médias entre os tratamentos, foi utilizado o teste Scott-Knott a 5\% de probabilidade.

\section{Resultados e Discussão}

As concentrações de MS, PB e FDN variaram $(\mathrm{P}<0,05)$, enquanto os teores de FDA, hemicelulose e cinzas foram semelhantes $(\mathrm{P}>0,05)$ entre os inoculantes utilizados (Tabela 2).

Os valores de MS obtidos nesta pesquisa variaram de 27,1 a 32,6\% e foram superiores aos reportados por Pedroso et al. (2007), 26,4\%, e Queiroz (2006), 23,1\%, mas foram inferiores aos reportados por Siqueira et al. (2007), de $35,0 \%$. As silagens com Lactobacillus plantarum apresentaram os maiores teores de matéria seca (32,6\%), que reduziram um ponto percentual no decorrer da fermentação. As demais silagens não diferiram entre si e apresentaram valor médio de $28,4 \%$, com redução média aproximada de dois pontos porcentuais com a fermentação (Tabela 2).

Em decorrência do alto crescimento de leveduras em silagens de cana-de-açúcar (Ávila, 2007), as perdas de MS durante a ensilagem desta forrageira podem decorrer do intenso metabolismo desses microrganismos. Segundo McDonald et al. (1991), a produção de etanol pelas leveduras é acompanhada pela perda acentuada de MS dos substratos na forma de $\mathrm{CO}_{2}$, além da perda de etanol por volatilização. Assim, redução nos teores de MS é indicativo de perdas durante a fermentação.

Neste trabalho, houve pequena redução nos teores de MS com a fermentação, em todas as silagens, o que pode estar associado ao tipo de silo utilizado (PVC), que era

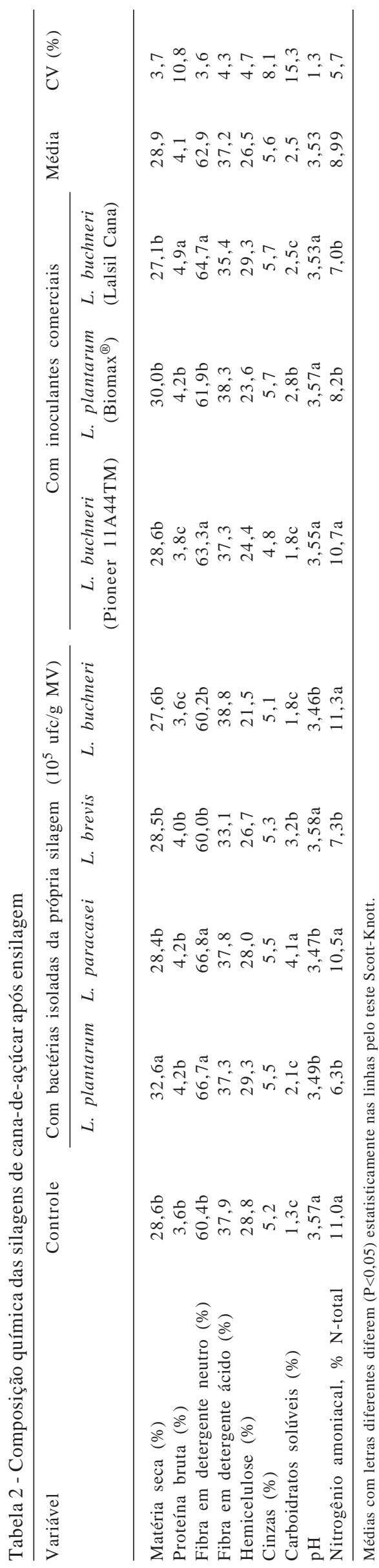

(c) 2009 Sociedade Brasileira de Zootecnia 
pequeno e propiciou compactação eficiente e fechamento rápido, evitando maiores perdas. Redução nos teores de MS também foi observada por outros autores, porém com variações entre os trabalhos. Siqueira et al. (2007), utilizando silos de PVC, verificaram perdas nos teores de MS de aproximadamente 6 pontos percentuais. Kung Jr. \& Stanley (1982) observaram redução de 30\% no teor de matéria seca durante a ensilagem de cana-de-açúcar sem aditivos em silos de escala de fazenda.

A concentração de PB (Tabela 2) foi significativamente maior na silagem com Lactobacillus buchneri (Lalsil Cana) (4,9\%), seguida das silagens com Lactobacillus plantarum, Lactobacillus paracase e Lactobacillus brevis (isoladas da própria silagem) e L. plantarum (Biomax), que foram semelhantes à da silagem controle.

Ao longo do período de fermentação, houve aumento médio na composição em PB, de 3,1 para 4,1\%, na forragem em comparação à silagem (Tabelas 1 e 2). Esse aumento durante a ensilagem ocorreu principalmente como consequência da utilização dos carboidratos solúveis, causando aumento percentual nos teores de PB. Segundo Rotz \& Muck (1994), o teor de PB pode sofrer aumento de 1 a 2 unidades percentuais na MS com esse processo. Nas silagens controle, com Lactobacillus buchneri e L. plantarum $\left(\right.$ Biomax $\left.^{\circledR}\right)$, as variações nos valores de PB foram menores. Na maioria dos trabalhos, não houve intensa degradação protéica em silagens de cana-de-açúcar, fato que pode ser explicado pela rápida queda do $\mathrm{pH}$ nestas silagens, inibindo o crescimento de enterobactérias e de clostrídios, principais microrganismos envolvidos na degradação protéica (Lindgren et al., 1985; McDonald et al., 1991).

Entre os componentes estruturais, somente a fração FDN diferiu entre silagens, com menores valores para as silagens controle e aquelas com Lactobacillus brevis e Lactobacillus buchneri (isoladas da própria silagem) e Lactobacillus plantarum(Biomax). As frações hemicelulose e FDA foram semelhantes $(\mathrm{P}>0,05)$ entre os inoculantes avaliados, com valores condizentes aos encontrados na literatura (Pedroso et al., 2006; Bravo Martins et al., 2006).

Os teores dos componentes estruturais e minerais aumentaram após a ensilagem. A silagem com o maior aumento nos teores de FDN foi aquela com Lactobacillus paracasei (7,8 unidades percentuais) e a menor, aquela com Lactobacillus brevis (0,89 unidades percentuais). Para a fração FDA, observou-se aumento de 14,07\% com a ensilagem da cana-de-açúcar. Aumentos ponderais de $27,13 \%$ nos teores de FDA foram relatados por Pedroso et al. (2005) em estudo do perfil de fermentação da silagem de cana-de-açúcar.
Aumentos percentuais da fração fibrosa do material ensilado em relação ao material original podem ser observados como resultado de perdas de constituintes solúveis em água (Kung Jr \& Stanley, 1982) juntamente com efluentes produzidos durante a fermentação (Bolsen, 1995) ou por perdas por gases. Nos trabalhos conduzidos com cana-deaçúcar, essas modificações têm sido associadas mais à perda de MS na forma de gases, em razão da fermentação alcoólica por leveduras, que às perdas por efluentes. Em trabalho realizado por Freitas et al. (2006), não houve produção de efluente e os autores concluíram que as modificações nos teores de MS, FDN e FDA decorreram das perdas de carboidratos solúveis na forma de gases e da produção da água de metabolismo.

Diferente das frações FDN e FDA, neste trabalho não se observou aumento da fração hemicelulose com a fermentação. Segundo Woolford (1984), durante a fermentação, a hemicelulose pode sofrer degradação por enzimas da própria planta ou então hidrólise ácida. Assim, a manutenção nos valores dessa variável indica degradação da hemicelulose em velocidade semelhante à perda de MS.

Os teores de cinzas em cana-de-açúcar são normalmente baixos. As concentrações de cinzas obtidas nesta pesquisa foram consideradas altas em comparação aos valores obtidos por Schmidt (2006) e Queiroz (2006). Essas diferenças podem estar relacionadas aos cultivares, à idade da planta e à adubação. Em silagens, variações nos teores de cinzas podem ser utilizadas para estimar as perdas de MS durante a fermentação, pois não sofrem alterações ao longo do processo fermentativo. Pedroso et al. (2005) observaram que os teores de cinzas nas silagens de cana aumentaram com a fermentação, em decorrência da perda de nutrientes na forma de gases e pelo efluente durante a ensilagem. Com isso, variações nos teores de cinzas e da fração fibrosa de silagens de cana de diferentes experimentos estão relacionadas também às perdas, influenciadas pelo tipo de silo, pelo tempo de fermentação e pela utilização ou não de inoculantes.

As silagens com Lactobacillus plantarum, Lactobacillus pacarasei e Lactobacillus buchneri (isoladas da própria silagem) foram aquelas com os menores valores de $\mathrm{pH}$ (Tabela 2). No caso das silagens com Lactobacillus plantarum e Lactobacillus paracasei, esses baixos valores estão relacionados à maior relação ácido lático:acético $(1,91)$ em comparação às demais silagens (dados não publicados). Esse comportamento era esperado, uma vez que esses inoculantes contêm espécies homofermentativas, entretanto não foi observado nas silagens com o inoculante comercial que continham bactéria homolática (LPB). 
Entre as silagens inoculadas com L. buchneri, aquela inoculada com a cepa isolada da cana-de-açúcar, tratamento Lactobacillus buchneri apresentou pH menor que o das silagens com inoculantes comerciais contendo esta mesma espécie de bactéria heterolática. Na avaliação do padrão de produção de ácidos graxos voláteis e ácido lático, a única diferença entre os três inoculantes contendo a espécie $L$. buchneri foi que, na cepa isolada, a concentração de ácido propiônico foi maior (1,34\%) que nas silagens com inoculante comercial (média de $0,13 \%$ ) (dados não publicados). Embora não tenha sido realizada a comprovação molecular da presença destas bactérias ao longo do processo fermentativo, é possível inferir que essa variação de $\mathrm{pH}$ foi decorrente da inoculação. Segundo Catchpoole \& Henzel (1971), existem diferenças entre as bactérias isoladas das silagens tropicais e as de clima temperado, pois, nas cepas isoladas, bactérias adaptadas à cana-de-açúcar, pode ter ocorrido maior eficiência na produção de ácidos graxos voláteis durante a fermentação que nas cepas oriundas de inoculantes comerciais.

Em geral, silagens inoculadas com Lactobacillus buchneri apresentam $\mathrm{pH}$ mais alto, como resultado da maior produção de ácido acético (Oude Elferink et al., 2001). Esse fato foi observado nas silagens com Lactobacillus plantarum e L. buchneri (Lalsil Cana), que continham essa espécie bacteriana. Todavia, apesar dos maiores valores de $\mathrm{pH}$ destas silagens, todas apresentaram valores de 3,46 a 3,58, dentro dos limites reportados na literatura para silagens de cana-de-açúcar (Pedroso et al., 2007; Siqueira et al., 2007).

As silagens controle, com Lactobacillus paracasei, Lactobacillu buchneri (isolado da própria silagem e Pioneer) apresentaram maiores teores de nitrogênio amoniacal (Tabela 2), enquanto as demais não diferiram $(\mathrm{P}>0,05)$ entre si. Em todas as silagens, os valores observados foram próximos ao limite sugerido por Van Soest (1994). Segundo esse autor, valores acima de $10 \%$ indicam que o processo de fermentação resultou em quebra excessiva de proteína em amônia. No entanto, em se tratando de uma forrageira com baixo valor protéico, em torno de 3,0\%, essa degradação não representa grandes perdas no valor final do alimento. Além disso, em silagem de cana, a redução do pH é rápida e, considerando que o pH é um dos fatores de maior importância na inibição de grande parte dos microrganismos que causam degradação protéica, como as enterobactérias e os clostrídeos, a concentração de nitrogênio amoniacal não é um fator preocupante na ensilagem desta forrageira.

Os teores de carboidratos solúveis residuais das silagens de cana-de-açúcar variaram de 1,3\%, para a silagem controle, até 4,1, para a silagem com bactéria homolática L. paracasei (Tabela 2). As silagens com inoculantes contendo bactérias da espécie L. buchneri apresentaram teores residuais de carboidratos solúveis numericamente superiores, porém semelhantes aos da silagem controle, o que difere dos resultados obtidos por Queiroz (2006), que observou maior preservação de carboidratos em silagens de cana adicionadas de $L$. buchneri, em comparação à silagem controle, cujos valores foram 3,7 e $1,8 \%$, respectivamente.

Em todas as silagens, o consumo dos carboidratos solúveis foi superior a $85 \%$, corroborando os dados da literatura, que indicam alta utilização dos carboidratos por bactérias e leveduras, presentes durante todo o processo fermentativo. Em geral, silagens com maiores concentrações de carboidratos estão associadas a maior eficiência de síntese de proteína microbiana no rúmen em comparação a silagens extensivamente fermentadas. Em comparação aos carboidratos solúveis, os produtos finais da fermentação da silagem têm pouco ou nenhum efeito como fonte energética para os microrganismos do rúmen (Chamberlain, 1987). No entanto, deve-se considerar que o ácido lático presente na silagem aumenta a proporção molar de propionato no rúmen (Jaakkola et al., 1991), reduzindo a relação entre ácidos graxos voláteis lipogênicos e glicogênicos (Huhtanen et al., 1997). Deve-se considerar também que silagens com maiores concentrações de carboidratos residuais, em geral, apresentam menor estabilidade aeróbia, exceto quando há algum fator que aumenta sua estabilidade.

Até aproximadamente 24 horas após a abertura dos silos, todas as silagens apresentaram temperaturas mais baixas e com valores próximos ao da temperatura ambiente (Figura 1). A partir daí, a temperatura da silagem sem inoculante aumentou até 48 horas de exposição ao ar, atingindo valores superiores a $40^{\circ} \mathrm{C}$. No período de 24 a 72 horas, as temperaturas das silagens inoculadas se mantiveram mais baixas que a da silagem controle, com variações entre os inoculantes. Temperaturas máximas próximas de $40^{\circ} \mathrm{C}$ também foram observadas por Junqueira (2006) em silagens de cana-de-açúcar durante a exposição aeróbia.

Entre as silagens inoculadas, aquelas com Lactobacillus plantarum, L. buchneri (Lalsil Cana) e Lactobacillus buchneri (Pioneer $11^{\mathrm{a}} 44 \mathrm{TM}$ ) aqueceram mais lentamente, ultrapassando 2 graus a temperatura ambiente aproximadamente 65 horas após a abertura dos silos (Figura 2). As modificações nas temperaturas das silagens com Lactobacillus brevis, L. paracasei e L. plantarum ocorreram de forma semelhante, ultrapassando 2 graus a temperatura ambiente após 48 horas de exposição ao ar. 

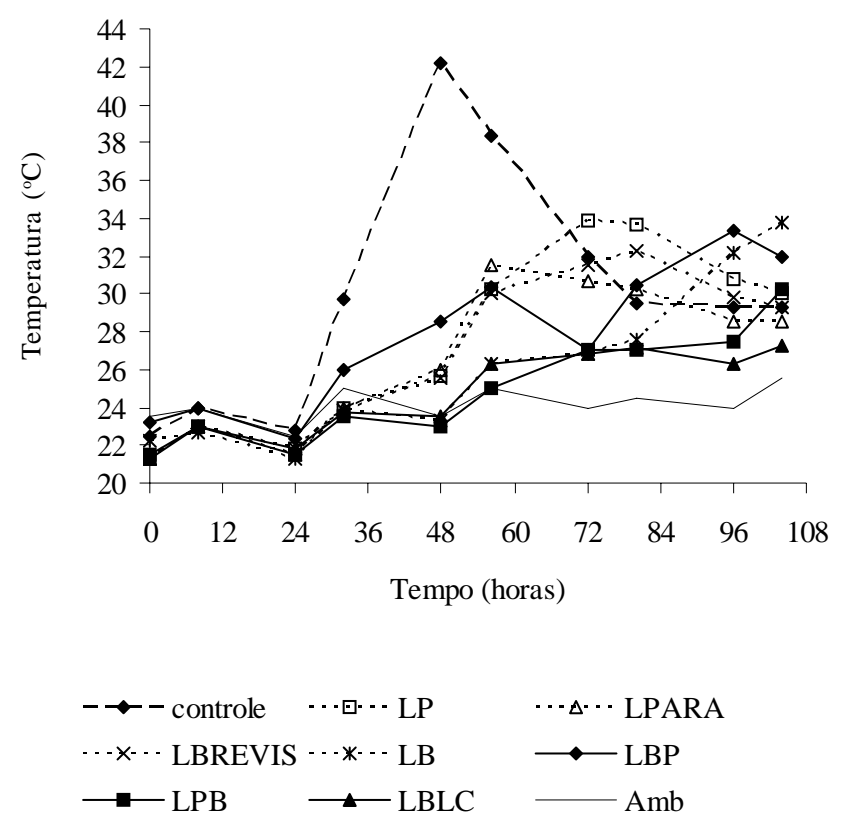

Figura 1 - Temperatura, após a abertura dos silos, de silagens de cana-de-açúcar tratadas com inoculantes.

Controle - sem inoculante; LP - L. plantarum $\left(10^{5} \mathrm{ufc} / \mathrm{g} \mathrm{MV}\right)$; LPARA - L. paracasei $\left(10^{5} \mathrm{ufc} / \mathrm{g} \mathrm{MV}\right)$; LBREVIS - L. brevis $\left(10^{5}\right.$ ufc/g MV); LB - L. buchneri (10 $10^{5}$ fc/g MV); LBP, LPB e LBLC silagens acrescidas de inoculantes comerciais; Amb - temperatura ambiente.
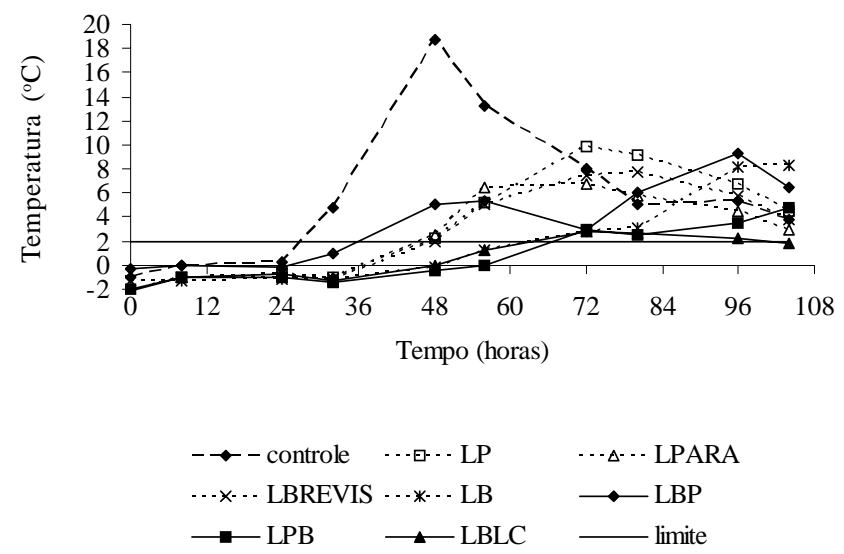

Figura 2 - Diferença entre a temperatura de silagens de cana-deaçúcar tratadas com inoculantes e a temperatura ambiente após a abertura dos silos.

Das silagens inoculadas, aquela com Lactobacillus buchneri (Pioneer $\left.11^{\mathrm{a}} 44 \mathrm{TM}\right)$ foi a que apresentou aquecimento mais rápido.

Não foi possível fazer uma comparação eficiente entre as silagens com apenas duas leituras diárias de temperatura. Segundo Figueiró et al. (2005), para silagens de cana-deaçúcar sem aditivos, para observar diferenças de apenas 1 ou $2^{\circ} \mathrm{C}$ no material em relação à temperatura ambiente, deveriam ser tomadas medidas de temperatura a cada 3 ou 5 horas. No entanto, em se tratando de silagens inoculadas, esse intervalo poderia ser maior ou menor, dependendo do padrão de fermentação. Neste trabalho, constam apenas as modificações temporais ocorridas nas silagens, mas os dados comprovam que todos os inoculantes reduziram o aquecimento das silagens de cana-de-açúcar. Esse efeito deve estar associado à presença de ácidos orgânicos, principalmente os ácidos propiônico (Moon, 1983) e acético (Ranjit \& Kung Jr., 2000), tendo em vista o poder fungicida destes ácidos. Danner et al. (2003) verificaram, em silagens de milho inoculadas com $L$ buchneri, $L$ brevis e $L$. plantarum, valores de 274, 72 e 26 horas de estabilidade, respectivamente, e relacionaram esses valores à produção de ácido acético durante a fermentação.

Todas as silagens foram consideradas instáveis, principalmente quando comparadas às silagens de milho e gramíneas, que são normalmente mais estáveis. Silagens de cana-de-açúcar, no entanto, apresentam baixa estabilidade, por sua alta concentração de carboidratos residuais e de ácido lático, que são substratos para microrganismos deterioradores. Assim, os valores encontrados neste estudo estão coerentes e condizentes com os descritos na literatura. Queiroz (2006) e Santos (2007) não detectaram influência da adição de $L$. buchneri sobre a estabilidade aeróbia de silagens de cana-de-açúcar, cujos valores médios foram de 37,7 e 35 horas; 41,5 e $42,5^{\circ} \mathrm{C}$, respectivamente.

A quebra da estabilidade com 40 ou 50 horas não tem grandes benefícios no manejo do silo. Contudo, como um dos objetivos neste trabalho foi avaliar o efeito de cepas isoladas e provenientes de inoculantes comerciais sobre a estabilidade das silagens, observou-se que, em geral, as silagens inoculadas apresentaram aquecimento mais lento. Essa observação é importante, uma vez que a capacidade de um inoculante de aumentar a estabilidade de uma silagem é uma característica a ser considerada na seleção de cepas para utilização na ensilagem (Saarisalo et al., 2006).

Em geral, os inoculantes influenciaram a composição química final das silagens, porém não foi possível ter conclusão definitiva, com base nestes parâmetros, sobre a influência dos inoculantes utilizados, ou seja, não foi possível comparar cepas homoláticas com cepas heteroláticas ou, então, cepas comerciais a cepas isoladas da própria silagem de cana-de-açúcar.

Os inoculantes estudados causaram diversas alterações na composição química da silagem. Cada um foi eficiente na melhoria de determinada característica estudada. No entanto, quando os inoculantes foram comparados com base na temperatura após abertura dos silos, observou-se, 
para todos os inoculantes, aumento mais lento da temperatura em relação à silagem controle. Como o aumento da temperatura é resultado do crescimento de microrganismos aeróbios facultativos que sobreviveram inativos na ausência do oxigênio (Nishino et al., 2003), provavelmente esses inoculantes inibem o crescimento desses microrganismos deterioradores, que, na silagem de cana-de-açúcar, são predominantemente leveduras, preservando nutrientes e melhorando o valor nutritivo da silagem após a abertura dos silos. Os inoculantes LBLC, LB e LPB tenderam a promover melhor temperatura após abertura dos silos.

Contudo, como as outras cepas isoladas também melhoraram a estabilidade das silagens, são necessários estudos mais aprofundados para avaliação dos efeitos da utilização destas cepas na melhoria do processo fermentativo da silagem de cana-de-açúcar.

\section{Conclusões}

A inoculação de cana-de-açúcar com bactérias homo e heterofermentativas do gênero Lactobacillus altera as características químicas das silagens de cana-de-açúcar. Silagens inoculadas com as cepas de L. buchneri isoladas da cana-de-açúcar e presentes no inoculante Lalsil Cana e a espécie $L$. plantarum do inoculante Biomax tendem a ser mais estáveis em condições de aerobiose.

\section{Agradecimentos}

Ao CNPq e à FAPEMIG, pelo apoio financeiro.

\section{Literatura Citada}

ASSOCIATION OF OFFICIAL AGRICULTURAL CHEMISTSAOAC. Official methods of analyses. 13.ed. Washington, D.C.: $1980.1015 p$.

ASSOCIATION OF OFFICIAL AGRICULTURAL CHEMISTSAOAC. Official methods of analyses. 15.ed. Virginia, 1990. v.1, 648p.

ÁVILA, C.L.S. Isolamento e uso de Lactobacillus buchneri na ensilagem de capim-mombaça e cana-de-açúcar. 2007. 175f. Tese (Doutorado em Zootecnia) - Universidade Federal de Lavras, Lavras, 2007.

BOLSEN, K.K. Silage: basic principles. In: BARNES, R.F.; MILLER, D.A.; NELSON, C.J. (Eds.) Forages. 5.ed. Ames: Iowa State University, 1995. p.163-176.

BRAVO-MARTINS, C.E.C.; CARNEIRO, L.; CASTRO-GÓMEZ, R.J.H. et al. Chemical and microbiological evaluation of ensiled sugar cane with different additives. Brazilian Journal of Microbiology, v.37, p.499-504, 2006.

CATHPOOLE, V.R.; HENZEL, E.F. Silage and silage-making from tropical herbage species. Herbage Abstracts, v.41, n.3, p.213-221, 1971.

CHAMBERLAIN, D.G. The silage fermentation in relation to the utilization of nutrients in the rumen. Process Biochemistry, n.22, p.60-63, 1987.
DANNER, H.; HOLZER, M.; MAYRHUBER, E. et al. Acetic acid increases stability of silage under aerobic conditions. Applied and Environmental Microbiology, v.69, n.1, p.562-567, 2003. DRIEHUIS, F.; OUDE ELFERINK, S.J.W.H.; SPOELSTRA, S.F. Anaerobic lactic acid degradation during ensilage of whole crop maize inoculated with Lactobacillus buchneri inhibits yeast growth and improves aerobic stability. Journal of Applied Microbiology, v.87, p.583-594,1999.

FERREIRA, D.F. Análises estatísticas por meio do SISVAR para windows versão 4.0. In: REUNIÃO ANUAL DA REGIÃO BRASILEIRA DA SOCIEDADE INTERNACIONAL DE BiOMetria, 45., 2000, São Carlos. Anais... São Carlos: Universidade Federal de São Carlos, 2000. p.225-258.

FERREIRA, D.A.; GONÇALVES, L.C.; MOLINA, L.R. et al. Características de fermentação da silagem de cana-de-açúcar tratada com uréia, zeólita, inoculante bacteriano e inoculante bacteriano/enzimático. Arquivo Brasileiro de Medicina Veterinária e Zootecnia, v.59, n.2, p.423-433, 2007.

FIGUEIRÓ, R.N.; SOUSA, D.P.; NUSSIO, L.G. et al. Frequências de determinação da temperatura em ensaio de estabilidade aeróbia. In: REUNIÃO ANUAL DA SOCIEDADE BRASILEIRA DE ZOOTECNIA, 42., 2005, Goiânia. Anais... Goiânia: Sociedade Brasileira de Zootecnia, 2005. (CD-ROM).

FILYA, I. The effect of Lactobacillus buchneri, with or withou homofermentative lactic acid bacteria, on the fermentation, aerobic stability and ruminal degradability of wheat, sorghum and maize silages. Journal of Applied Microbiology, v.95, n.5, p.1080-1086, 2003.

FREITAS, A.W.P.; PEREIRA, J.C.; ROCHA, F.C. et al. Avaliação da qualidade nutricional da silagem de cana-de-açúcar com aditivos microbianos e enriquecida com resíduo da colheita de soja. Revista Brasileira de Zootecnia, v.35, n.1, p.38-47, 2006.

HARRIS, L.E. Os métodos químicos e biológicos empregados na análise de alimentos. Gainesville: University of Florida, 1970. 150p.

HAMMES, W.P.; HERTEL, C. The genera Lactobacillus and Carnobacterium. Disponivel em: <http://link.springer-ny.com/ link/service/books/10125/> Acesso em: 20/5/2005.

HOLT, J.G.; KRIEG, N.R.; SNEATH, P.H.A. et al. Bergey's manual of determinative bacteriology. 9.ed. Baltimore: Williams \& Wilkins, 1994. 787p.

HUHTANEN, P.J.; MiETTINEN, H.O.; TOIVONEN, V.F.J. Effects of silage fermentation and post-ruminal casein supplementation in lactating dairy cows: 1 . Diet digestion and milk production. Journal of Science Food Agriculture, v.74, p.450-458, 1997.

JAAKKOLA, S.; HUHTANEN, P.; HISSA, K. The effect of cell wall degrading enzymes or formic acid on fermentation quality and on digestion of grass silage of cattle. Grass and Forage Science, v.46, p.75-87, 1991.

JUNQUEIRA, M.C. Aditivos químicos e inoculantes microbianos em silagens de cana-de-açúcar: perdas na conservação, estabilidade aeróbia e o desempenho de animais. 2006. 98f. Dissertação (Mestrado em Agronomia) - Escola Superior de Agricultura “Luiz de Queiroz” - Universidade de São Paulo, Piracicaba, 2006.

KUNG JR., L.; STANLEY, R.W. Effect of stage of maturity on the nutritive value of whole-plant sugarcane preserved as silage. Journal of Animal Science, v.54, p.689-696, 1982.

LIDGREN, S.; PETTERSSON, K.; KASPERSON, A. Microbial dynamics during aerobic deterioration of silages. Journal of Science Food Agriculture, v.36, n.8, p.765-774, 1985.

McDONALD, P.; HENDERSON, A.R.; HERON, S.J. Biochemistry of silage. 2.ed. Marlow: Chalcombe, 1991. 340p.

MOLINA, L.R.; FERREIRA, D.A.; GONÇALVES, L.C. et al. Padrão de fermentação da silagem de cana-de-açúcar submetida a diferentes tratamentos. In: REUNIÃO ANUAL DA SOCIEDADE BRASILEIRA DE ZOOTECNIA, 39., 2002, Recife. Anais... Recife: Sociedade Brasileira de Zootecnia, 2002. (CD-ROM). 
MOON, N.J. Inhibition of the growth of acid tolerant yeasts by acetate, lactate and propionate and their synergistic mixtures. Journal of Applied Bacteriology, v.55, p.453-460, 1983.

NISHINO, N.; YOSHIDA, M.; SHIOTA, H. et al. Accumulation of 1,2-propanediol and enhancement of aerobic stability in whole crop maize silage inoculated with Lactobacillus buchneri. Journal of Applied Microbiology, v.94, p.800-807.

NUSSIO, L.G.; SCHMIDT, P.; PEDROSO, A.F. Silagem de canade-açúcar In: FORRAGICULTURA E PASTAGENS: temas em evidência - sustentabilidade, 2003, Lavras. Anais... Lavras: Editora UFLA, 2003. p.49-72.

OUDE ELFERINK, S.J.W.H.; KROONEMAN, J.; GOTTSCHAL, J.A. et al. Anaerobic conversion of lactic acid to acetic acid and 1,2-propanediol by Lactobacillus buchneri. Applied and Environmental Microbiology, v.67, n.1, p.125-132, 2001.

PEDROSO, A.F.; NUSSIO, L.G.; BARIONI JR., W. et al. Performance of holstein heifers fed sugarcane silages treated with urea, sodium benzoate or Lactobacillus buchneri. Pesquisa Agropecuária Brasileira, v.41, n.4, p.649-654, 2006.

PEDROSO, A.F.; NUSSIO, L.G.; LOURES, D.R.S. et al. Efeito do tratamento com aditivos químicos e inoculantes bacterianos nas perdas e na qualidade de silagens de cana-de-açúcar. Revista Brasileira de Zootecnia, v.36, n.3, p.558-564, 2007.

PEDROSO, A.F.; NUSSIO, L.G.; PAZIANI, S.F. et al. Fermentation and epiphytic microflora dynamics in sugar cane silage. Scientia Agricola, v.62, n.5, p.427-432, 2005.

PLAYNE, M.J.; McDONALD, P. The buffering constituints of herbage. Journal of Food Science and Agriculture, v.17, n.6, p.264-268, 1966.

QUEIROZ, O.C.M. Associação de aditivos microbianos na ensilagem e o desempenho de vacas em lactação recebendo silagem de cana-de-açúcar comparada a um volumoso tradicional. 2006. 122f. Tese (Doutorado em Agronomia) -
Escola Superior de Agricultura “Luiz de Queiroz”, Universidade de São Paulo, Piracicaba, 2006.

RANJIT, N.K.; KUNG JR., L. The effect of Lactobacillus buchneri, Lactobacillus plantarum, or a chemical preservative on the fermentation and aerobic stability of corn silage. Journal of Dairy Science, v.83, p.526-535, 2000.

ROTZ, C.A.; MUCK, R.E. Changes in forage quality during harvest and storage. In: FAHEY JR., G.C.; COLLINS, M.; MERTENS, D.R. et al. (Eds.) Forage quality, evaluation and utilization. Madison: ASA; CSSA; SSSA, 1994. p.828-868.

SAARISALO, E.; SKYTTA, E.; HAIKARA, A. et al. Screening and selection of lactic acid bacteria strains suitable for ensiling grass. Journal of Applied Microbiology, v.102, p.327-336, 2007.

SCHMIDT, P. Perdas fermentativas na ensilagem, parâmetros digestivos e desempenho de bovinos de corte alimentados com rações contendo silagens de cana-de-açúcar. 2006. 228f. Tese (Doutorado em Agronomia) - Escola Superior de Agricultura Luiz de Queiroz-Universidade de São Paulo, Piracicaba, 2006.

SILVA, D.J. Análise de alimentos: métodos químicos e biológicos. Viçosa, MG: Universidade Federal de Viçosa, 1990. 166p.

SIQUEIRA, G.R.; REIS, R.A.; SCHOCKEN-ITURRINO, R.P. et al. Associação entre aditivos químicos e bacterianos na ensilagem de cana-de-açúcar. Revista Brasileira de Zootecnia, v.36, n.4, p.789-798, 2007.

VALADARES FILHO, S.C. Digestibilidade aparente e locais de digestão da matéria seca, energia e carboidratos de feno de soja perene. 1981. 88f. Tese (Doutorado em Zootecnia) - Escola de Veterinária da Universidade Federal de Minas Gerais, Belo Horizonte, 1981.

Van SOEST, P.J. Nutritional ecology of the ruminants. 2.ed Ithaca: Cornell University, 1994. 476p.

WOOLFORD, M.K. The silage fermentation. New York: M. Dekker, 1984. 350p. 